\section{Incidence and risk factors for retinopathy of prematurity in very low and in extremely low birth weight infants in a unit-based approach in southern Brazil}

JB Fortes Filho, GU Eckert, L Procianoy, CK Barros and RS Procianoy
Conclusion This study showed reduced survival rates, high incidence of ROP, and a greater need of treatment among ELBW infants as compared to VLBW babies admitted in this institution.

Eye (2009) 23, 25-30; doi:10.1038/sj.eye.6702924; published online 6 July 2007

Keywords: prematurity; retinopathy of prematurity; extremely low birth weight; very low birth weight; risk factors; prevention of blindness

\section{Introduction}

The incidence of retinopathy of prematurity (ROP) has been the focus of extensive studies worldwide owing to the increasing survival rates now observed among premature infants. Although the incidence and severity of this condition have been decreasing in developed countries over the past two decades, these two factors are showing an increase in developing nations. ${ }^{1}$ The most important groups of preterm babies developing this condition nowadays are very low birth weight (VLBW) preterm infants (birth weight (BW) $>1000 \mathrm{~g}$ and $\leqslant 1500 \mathrm{~g}$ ) and extremely low birth weight (ELBW) preterm infants (BW $\leqslant 1000 \mathrm{~g}$ ). ${ }^{2}$

The Brazilian guidelines for ROP screening were established by the Brazilian Ophthalmology Council, the Brazilian Paediatric Ophthalmology Society, and the Brazilian Society of Paediatrics after the first
Departments of Ophthalmology and Paediatrics, Newborn Section, Medical School, Federal University of Rio Grande do Sul and Hospital de Clinicas de Porto Alegre, Porto Alegre, Brazil

Correspondence: JBF Filho, Department of Ophthalmology, Medical School Federal University of Rio Grande do Sul, Rua Jaragua, 672 ap 202, Porto Alegre, RS 90450140, Brazil

Tel: + 5551333347 96; Fax: + 555132229292 . E-mail: jbfortes@cursohbo. com.br

Received: 17 December 2006

Accepted in revised form: 8 June 2007 Published online: 6 July 2007 
ROP Workshop, held in Rio de Janeiro in 2002. The joint statement issued at the time recommended ROP screening for all infants with $\mathrm{BW} \leqslant 1500 \mathrm{~g}$ or gestational age $(\mathrm{GA}) \leqslant 32$ weeks or for any infant with $\mathrm{BW}>1500 \mathrm{~g}$, presenting with an unstable clinical course and designated as a high-risk case by the attending neonatologist. The incidence of blindness or severe visual impairment due to ROP in Brazil is estimated to be around 500-1500 cases/year. ${ }^{3,4}$

Over the last years, epidemiological studies have shown falling mortality rates among ELBW infants in both developed and middle-income countries. The incidence of ROP and the need for laser treatment for this condition in the ELBW group were higher as well. ${ }^{5-7}$

The aim of this study was to analyse the survival rates, possible risk factors, and the incidence of ROP among ELBW and VLBW preterm infants admitted in a teaching hospital in southern Brazil.

\section{Materials and methods}

This prospective cohort study included all preterm infants with BW $\leqslant 1500 \mathrm{~g}$ and/or GA $\leqslant 32$ weeks admitted to Hospital de Clinicas de Porto Alegre (HCPA), a teaching and tertiary referral hospital, between October 2002 and December 2006. The incidence of ROP was analysed among ELBW (BW $\leqslant 1000 \mathrm{~g}$ ) and VLBW infants (BW > $1000 \mathrm{~g}$ and $\leqslant 1500 \mathrm{~g}$ ). Babies with BW >1500 g and $\leqslant 32$ weeks of GA examined during the screening for ROP (according to the Brazilian guidelines) were included in the VLBW group.

All patients were first examined in the sixth week of life and follow-up examinations were performed to investigate sequential retinal changes using the International Classification of ROP of 1984/1987.,.$^{89}$ Neonates who died before the first ophthalmologic examination were excluded.

Pupils were dilated with tropicamide $0.5 \%$ and phenylephrine $2.5 \%$ eye drops, instilled $1 \mathrm{~h}$ before examination. Indirect ophthalmoscopy was performed using a $28 \mathrm{D}$ lens (Nikon, Melville, NY, USA) and lid speculum (Alfonso Eye speculum, Storz, Bausch \& Lomb Inc., CA, USA). All patients were first screened in the neonatal intensive care unit (NICU). After that, they were followed as outpatients until full vascularization of the retina had reached zone 3 or until full remission of ROP after treatment. All patients with stage 3 threshold ROP were treated with diode laser photocoagulation of the peripheral avascular retina under general anaesthesia or sedation. The worst stage of ROP was recorded. Ophthalmic examinations were always performed by the same ophthalmologist qualified for ROP screening (JBFF).
The main outcome studied was a diagnosis of any stage of ROP in the ELBW and VLBW groups. Perinatal variables considered for the study were BW, GA, gender, use of oxygen therapy and mechanical ventilation, single or multiple pregnancies, use of surfactant, indomethacin and erythropoietin therapy, sepsis, meningitis or intraventricular haemorrhage, and necessity of blood transfusions.

Statistical analysis was performed using the Statistical Package for Social Sciences software (SPSS 13.0 for Windows, SPSS Inc., Chicago, IL, USA). For the incidence of ROP, 95\% confidence intervals (CI) were calculated. The $\chi^{2}$ test was used to compare the clinical outcomes and odds ratio (OR) in both groups. Student's unpaired $t$-test was used to compare continuous data. A logistic regression model was performed and the adjusted OR (95\% CI) was obtained for the risk factors included in the model. The study protocol was approved by the Ethics Committee of the HCPA (No. 03-247).

\section{Results}

From October 2002 to December 2006, there were 530 infants with BW $\leqslant 1500 \mathrm{~g}$ admitted to HCPA, of whom 380 survived until discharge (71. $7 \%$ ), and 353 babies out of that total were screened for ROP and enrolled in this study $(92.6 \%)$.

Eighty-eight prematures fell into the ELBW group and 264 into the VLBW group. The mean BW among the ELBW group was $825.34 \mathrm{~g}$ (standard deviation (SD): 128.3) and $1329.05 \mathrm{~g}$ in the VLBW (SD: 191.5), $P<0.001$. The mean GA among ELBW group was 28.5 weeks (SD: 2.1) and 30.9 weeks in the VLBW group (SD: 1.9), $P=0.152$

The survival rate in the ELBW group was $47.8 \%$ and in the VLBW group, it was $88.7 \%$ during the period covered by this study. The baseline characteristics of the study population are shown in Table 1.

The overall incidence of ROP and the incidence in each stage in both the groups are shown in Table 2. The incidence of ROP among ELBW babies was $48.9 \%(95 \%$ CI: $38.1-59.7 \%$ ) and $18.2 \%$ (95\% CI: $13.7-23.4 \%)$ for

Table 1 Baseline characteristics of the study population

\begin{tabular}{lccr}
\hline & ELBW mean (SD) & VLBW mean (SD) & P-value \\
\hline Number of patients & 88 & 264 & \\
$\begin{array}{l}\text { Number of male } \\
\text { gender (\%) }\end{array}$ & $39(44.3 \%)$ & $114(43.2 \%)$ & 0.179 \\
Birth weight, g & $825.34(128.3)$ & $1329.05(191.5)$ & $<0.001$ \\
Gestational age, & $28.5(2.1)$ & $30.9(1.9)$ & $<0.001$ \\
$\quad$ & & & \\
weeks & & &
\end{tabular}

Abbreviations: ELBW, extremely low birth weight; VLBW, very low birth weight. 
VLBW babies $(P<0.001)$. Threshold disease affected $17 \%$ of the infants in the ELBW group and $2.3 \%$ in the VLBW group $(P<0.001)$.

Table 3 lists the highest of the ROP stages found in each BW group. Fifteen babies whose BW was less than $1000 \mathrm{~g}$ displayed severe ROP (stage 3 or higher) and only six neonates whose BW was $1001 \mathrm{~g}$ or higher showed treatable ROP.

The need for treatment with diode laser in both groups is listed in Table 4 . Fifteen out of 21 preterm babies with threshold disease fell into the ELBW group. The anatomic features showed complete regression of severe ROP in 19 treated patients, while one showed a progression of the disease to stage $4 \mathrm{~A}$ of ROP, requiring scleral buckling. One patient dropped out of treatment after discharge and his condition progressed to stage 5 ROP.

Perinatal risk factors for ROP are summarized in Table 5. Univariate analysis indicates that GA, BW, the use of erythropoietin and indomethacin, blood transfusions, and intraventricular haemorrhage were associated with ROP in this cohort of 352 patients. After logistic regression, the most important adjusted risk factors in this cohort of patients were BW (OR: 1.002; 95\% CI:1.001-1.003; $P=0.003$ ), GA (OR: 1.254; 95\% CI: $1.082-1.455 ; P=0.003)$, and use of erythropoietin (OR: 2.486; 95\% CI: 1.182-5.231; $P=0.016$ ).

Table 2 Incidence of ROP among ELBW and VLBW infants between 2002 and 2006

\begin{tabular}{lcc}
\hline & $E L B W$ & $V L B W$ \\
\hline Non-ROP & $45(51.1 \%)$ & $216(81.8 \%)$ \\
ROP* & $43(48.9 \%)$ & $48(18.2 \%)$ \\
ROP 1 & $12(13.6 \%)$ & $29(11.0 \%)$ \\
ROP 2 & $16(18.8 \%)$ & $13(5.0 \%)$ \\
ROP 3* & $13(14.8 \%)$ & $6(2.3 \%)$ \\
ROP 4* & $1(1.1 \%)$ & $0(0.0 \%)$ \\
ROP 5* & $1(1.1 \%)$ & $0(0.0 \%)$ \\
Total & 88 & 264 \\
\hline
\end{tabular}

Abbreviations: ELBW, extremely low birth weight; ROP, retinopathy of prematurity; ROP* $P<0.001$; ROP $3^{*}$ and more; threshold ROP $P<0.001$; VLBW, very low birth weight.

Table 3 ROP stages according to the birth weight for the whole cohort

\begin{tabular}{lrrrrrrr}
\hline Birth weight & $\begin{array}{r}\text { Non- } \\
\text { ROP }\end{array}$ & $\begin{array}{r}\text { ROP } \\
1\end{array}$ & $\begin{array}{c}\text { ROP } \\
2\end{array}$ & $\begin{array}{c}\text { ROP } \\
3\end{array}$ & $\begin{array}{c}\text { ROP } \\
4\end{array}$ & $\begin{array}{r}\text { ROP } \\
5\end{array}$ & Total \\
\hline $5500 \mathrm{~g}$ & 0 & 0 & 0 & 0 & 0 & 0 & 0 \\
$501-750 \mathrm{~g}$ & 10 & 2 & 8 & 5 & 0 & 1 & 26 \\
$751-1000 \mathrm{~g}$ & 36 & 10 & 8 & 8 & 1 & 0 & 63 \\
$1001-1500 \mathrm{~g}$ & 175 & 27 & 13 & 6 & 0 & 0 & 221 \\
$>1500 \mathrm{~g}$ & 40 & 2 & 0 & 0 & 0 & 0 & 42 \\
Total & 261 & 41 & 29 & 19 & 1 & 1 & 352 \\
\hline
\end{tabular}

Abbreviation: ROP, retinopathy of prematurity.

\section{Discussion}

The World Health Organization Vision 2020 programme has identified ROP as an important cause of blindness in countries with low infant mortality rates. ${ }^{10}$ Gilbert et al suggest that ROP is more prevalent in neonates born under $1000 \mathrm{~g}$ in industrialized countries. The disease is also emerging as a major cause of childhood blindness in middle-income countries like Brazil and in many other places in Latin America, Asia, and Eastern Europe, owing to the increasing survival rates among ELBW and VLBW prematures. ${ }^{5,10-12}$ Survival rates among preterm babies born with GA of 27-28 weeks have been reported to be as high as $90 \%$, although the numbers vary widely across countries. ${ }^{13}$

Studies suggest that the incidence and severity of ROP show an inverse relationship with BW and GA, ${ }^{14}$ with few cases diagnosed in babies weighing over $1500 \mathrm{~g}$ or babies whose GA was > 32 weeks at birth. Severe ROP has a higher incidence among infants born with GA $<28$ weeks or BW $<1000 \mathrm{~g}$. However, severe ROP is also reported in babies born at 34-35 weeks with BW $1500 \mathrm{~g}$ or more, ${ }^{15}$ especially when postnatal systemic complications occur, as shown in studies in India, China, and Lithuania. ${ }^{16-20}$

HCPA is a level 3 hospital located in Porto Alegre, a city of 3 million inhabitants in southern Brazil. The hospital's NICU has 20 intensive-care beds. In the period covered by this study, the NICU received 530 babies with BW $<1500 \mathrm{~g}$, 380 of whom survived. Three hundred and fifty-two patients were screened for ROP following the Brazilian guidelines (92.6\%).

Previous ROP studies at $\mathrm{HCPA}^{21,22}$ showed a prevalence of $28.5 \%$ in preterm infants with BW $<1500 \mathrm{~g}$ or GA $\leqslant 32$ weeks between 2002 and 2004. The present study showed an ROP incidence of $48.9 \%$ in ELBW babies. Survival rates among VLBW and ELBW patients at HCPA were 88.7 and $47.8 \%$, respectively, during the period studied. In Brazil, Graziano et $a l^{23}$ found a prevalence of $29.1 \%$ of any stage of ROP among 102 premature babies with $\mathrm{BW}<1500 \mathrm{~g}$. That study drew attention to the high prevalence rates of ROP among babies with $\mathrm{BW}<1000 \mathrm{~g}(78.5 \%)$ and whose GA was $<30$ weeks $(72.7 \%)$. Moraes et $a^{24}$ showed an ROP incidence of $90 \%$ in preterm babies whose BW was $<1000 \mathrm{~g}$. Although these important Brazilian unit-based studies date from the 1990s, the incidence of ROP found in our present study is considerably lower in spite of the higher survival rates of premature infants observed today.

A study in Tokyo, Japan, reported survival rates of $85.6 \%$ for preterm babies born in 2002 in a group whose mean GA was approximately 26.74 weeks and mean BW was approximately $782.25 \mathrm{~g}$. Those authors ${ }^{25}$ reported that $86.1 \%$ of those babies developed ROP and $41 \%$ of 
Table 4 Treatable ROP among ELBW and VLBW groups and GA at pre-threshold ROP and at threshold ROP

\begin{tabular}{|c|c|c|c|c|c|c|c|}
\hline & $B W$ & $G A$ & Gender & Group & ROP zone & GA at pre-threshold ROP & $G A$ at treatment threshold $R O P$ \\
\hline & 620 & 25 & $\mathrm{~F}$ & ELBW & II & 34 & 36 \\
\hline & 625 & 26 & $\mathrm{~F}$ & ELBW & II & 34 & 36 \\
\hline & 635 & 27 & $\mathrm{~F}$ & ELBW & II & 35 & 36 \\
\hline & 700 & 26 & $\mathrm{~F}$ & ELBW & II & 35 & 36 \\
\hline & 710 & 26 & $\mathrm{~F}$ & ELBW & II & 35 & 36 \\
\hline & 750 & 28 & $\mathrm{~F}$ & ELBW & II & 37 & 38 \\
\hline & 755 & 25 & $\mathrm{~F}$ & ELBW & II & 35 & 36 \\
\hline & 780 & 31 & $\mathrm{M}$ & ELBW & II & 37 & 40 \\
\hline & 850 & 28 & $\mathrm{~F}$ & ELBW & II & 36 & 37 \\
\hline & 870 & 30 & M & ELBW & II & 38 & 40 \\
\hline & 890 & 26 & $\mathrm{~F}$ & ELBW & II & 35 & 37 \\
\hline & 900 & 31 & $\mathrm{M}$ & ELBW & II & 38 & 40 \\
\hline & 920 & 30 & $\mathrm{M}$ & ELBW & II & 36 & 38 \\
\hline & 935 & 30 & $\mathrm{M}$ & ELBW & II & 36 & 37 \\
\hline & 990 & 29 & $\mathrm{M}$ & ELBW & II & 38 & 39 \\
\hline & 1055 & 27 & $\mathrm{M}$ & VLBW & II & 38 & 39 \\
\hline & 1080 & 26 & $\mathrm{~F}$ & VLBW & II & 35 & 37 \\
\hline & 1230 & 31 & $\mathrm{M}$ & VLBW & II & 37 & 40 \\
\hline & 1260 & 28 & $\mathrm{M}$ & VLBW & II & 36 & 37 \\
\hline & 1315 & 32 & $\mathrm{M}$ & VLBW & II & 39 & 41 \\
\hline & 1500 & 30 & $\mathrm{~F}$ & VLBW & II & 39 & 40 \\
\hline Mean & 928.4 & 27.9 & & & & 36.3 & 37.9 \\
\hline Median & 890 & 27 & & & & 36 & 37 \\
\hline SD & 243.8 & 2.4 & & & & 1.6 & 1.7 \\
\hline
\end{tabular}

Abbreviations: BW, birth weight; ELBW, extremely low birth weight;F: female gender; GA, gestational age; M, male gender; ROP, retinopathy of prematurity; SD, standard deviation; VLBW, very low birth weight.

Table 5 Perinatal risk factors for ROP for the whole cohort

\begin{tabular}{|c|c|c|c|}
\hline Univariate analysis & $R O P \mathrm{n}=91(\%)$ & Non-ROP $\mathrm{n}=261(\%)$ & P-value \\
\hline Male gender & $57(62.6)$ & $142(54.4)$ & 0.18 \\
\hline Erythropoietin & 79 (86.8) & $199(76.2)$ & 0.03 \\
\hline Multiple gestation & $16(17.6)$ & $38(14.6)$ & 0.50 \\
\hline Intraventricular haemorrhage & $23(25.3)$ & 38 (14.6) & 0.02 \\
\hline Oxygen in mechanical ventilation & $54(59.3)$ & $126(48.5)$ & 0.09 \\
\hline Indomethacin & $38(41.8)$ & $79(30.3)$ & 0.05 \\
\hline Surfactant & $50(54.9)$ & $115(44.1)$ & 0.09 \\
\hline Sepsis & $69(75.8)$ & $178(68.2)$ & 0.19 \\
\hline Meningitis & $6(6.6)$ & $23(8.8)$ & 0.66 \\
\hline Blood transfusions & $51(56)$ & $107(41)$ & 0.01 \\
\hline Birth weight ${ }^{a}$ & $1053.3 \pm 281.4$ & $1,253.4 \pm 263.9$ & $<0.001$ \\
\hline Gestational age $^{a}$ & $29.1 \pm 2.3$ & $30.7 \pm 2.1$ & $<0.001$ \\
\hline Multivariate analysis & OR & $95 \% C I$ & P-value \\
\hline Birth weight & 1.002 & $1.001-1.003$ & 0.003 \\
\hline Gestational ge & 1.254 & $1.082-1.455$ & 0.003 \\
\hline Erythropoietin & 2.486 & $1.182-5.231$ & 0.016 \\
\hline Intraventricular haemorrhage & 1.884 & $0.991-3.581$ & 0.053 \\
\hline
\end{tabular}

Abbreviations: $\mathrm{CI}$, confidence interval; OR, odds ratio; ROP, retinopathy of prematurity.

${ }^{\mathrm{a}}$ Data showed in mean $\pm \mathrm{SD}$.

them were treated with laser, a much higher percentage of cases of treatable ROP. In that report, six patients $(4.9 \%)$ showed retinal detachment. Both the survival rate and the incidence of ROP in the Japanese study were much higher than the values observed in Brazil.
In USA, Hussain et $a l^{26}$ performed a retrospective assessment of 950 babies between the years 1989 and 1997 and found an incidence of ROP of $21.3 \%$, of whom only $4.6 \%$ developed stage 3 disease or worse. In this group, none of the patients born with BW >1000 g or GA 
$>28$ weeks needed laser or surgical intervention. Another US study by O'Connor $e t a l^{27}$ identified an increase in the overall occurrence of threshold ROP from 2 to $5 \%$ between 1999 and 2000. Infants with BW $<750 \mathrm{~g}$ were found to be at the highest risk for ROP. The findings from those studies in the USA are similar to those observed at HCPA, where $5.8 \%$ of all screened babies developed threshold disease. In our cohort, only six babies $(2.3 \%)$ with $\mathrm{BW}>1000 \mathrm{~g}$ needed laser treatment while $17.0 \%$ of the ELBW group required treatment.

The screening guidelines for ROP adopted in Brazil after 2002 state that every newborn with BW $\leqslant 1500 \mathrm{~g}$ or $\mathrm{GA} \leqslant 32$ weeks should be screened. In the present study, 39 patients with BW $>1505 \mathrm{~g}$ and 30 patients with GA $>32$ weeks were examined. None of these presented severe ROP or threshold disease. However, this should not be understood as a claim that current screening recommendations are too strict for Brazil. Although the incidence of treatable ROP in the VLBW group was lower $(2.3 \%)$, the screening and treatment of those babies prevented disease progression in six patients $(6 / 238)$ in the period covered by this study.

Recent studies suggest that ROP screening guidelines and the moment at which the first examination should be performed in ELBW patients are in need of revision, and advocate to start screening in the fourth week of life in these patients because all cases of threshold ROP were recorded before the 34th week of the infant's corrected age. ${ }^{28-30}$ In the HCPA study reported here, the mean GA for threshold disease was 37.9 weeks (SD:1.7) and the mean GA for pre-threshold diagnosis was 36.3 weeks (SD:1.6), considering the whole cohort of treated patients. Of the 21 patients who developed threshold disease at HCPA, there were 15 ELBW babies. Despite the higher incidence of threshold disease in the ELBW population, none of them developed severe posterior disease or zone 1 ROP.

Many papers analysed perinatal risk factors for ROP. Pat ${ }^{31}$ clearly demonstrated the causal effects of the administration of oxygen on the development of ROP. At HCPA, to accomplish tighter control of oxygen therapy, strict guidelines are applied. All neonate in critical condition is permanently controlled in his clinical aspects and by the use of pulse oximetry with a recommended saturation pressure between 88 and $94 \%$. All NICU staff is regularly trained on the relationship between hyperoxemia and ROP. This training is helpful because it is possible to control and prevent the occurrence of severe ROP in most cases only by carefully monitoring hyperoxia and avoiding fluctuations. ${ }^{32,33}$

In the present study, the main risk factors associated with ROP were low BW and low GA and the use of erythropoietin. The anaemia of prematurity is commonly associated with low reticulocyte counts and deficient erythropoietin production. Since anaemia may decrease the amount of available oxygen to a critical level, preterm infants receive frequent blood transfusions. ${ }^{34}$ There are studies confirming the role of blood transfusions on ROP in infants with BW of less than $1250 \mathrm{~g} .{ }^{35,36}$ The use of recombinant human erythropoietin to reduce the need for blood transfusions in preterm infants has been suggested. ${ }^{37,38}$ Recently, cumulative recombinant erythropoietin exposure (as total 6-week dose) in infants born prematurely was associated with an increased risk for ROP. The non-hematopoietic properties of erythropoietin may account for these findings. ${ }^{39}$ In our cohort of 352 premature babies, we found that $86.8 \%$ of the 91 patients with ROP and $76.2 \%$ of the 261 patients who do not develop ROP used the recombinant human erythropoietin ( $P=0.03$, Table 5$)$.

The higher survival rate and the significantly higher incidence of severe ROP requiring treatment in ELBW preterm babies indicate that this group of patients should receive special attention by ophthalmologists and neonatologists when screening for the disease. The Brazilian guidelines for ROP screening adopted at HCPA after 2002 were shown to be effective in detecting all cases of threshold disease that needed laser treatment and this has helped to prevent blindness in 20 neonates since then. It is important to note that the present study is a unit-based approach and the observations herein cannot be applied to patients receiving care in a different setting.

\section{Acknowledgements}

The authors certify that the content has not been published or submitted for publication elsewhere. Authors also certify that the protocol for the research project has been approved by a suitably constituted Ethics Committee of the institution within which the work was undertaken and that it conforms to the provisions of the Declaration of Helsinki in 1995 (as revised in Edinburgh 2000). Authors declare no financial support or relationships that may pose a conflict of interest.

\section{References}

1 Wheatley CM, Dickinson JL, Mackey DA, Craig JE, Sale MM. Retinopathy of prematurity: recent advances in our understanding. Br J Ophthalmol 2002; 86: 696-700.

2 Rowlands E, Ionides AC, Chinn S, Mackinnon H, Davey CC. Reduced incidence of retinopathy of prematurity. $\mathrm{Br} J$ Ophthalmol 2001; 85: 933-935.

3 Graziano RM, Leone CR. Frequent ophthalmologic problems and visual development of extremely preterm newborn infants. J Pediatr (Rio J) 2005; 81: S95-S100. 
4 Fortes Filho JB, Barros CK, Lermann VL, Eckert GU, Costa MC, Procianoy RS. Prevention of blindness due to retinopathy of prematurity at Hospital de Clinicas de Porto Alegre, Brazil: incidence, risk factors, laser treatment and outcomes from 2002 to 2006. Acta Medica Lituanica 2006; 13: 130-136.

5 Foster A, Gilbert C. Epidemiology of childhood blindness. Eye 1992; 6: 173-176.

6 Gilbert C. Retinopathy of prematurity: epidemiology. J Comm Eye Health 1997; 10: 22-24.

7 Gilbert C. Worldwide causes of childhood blindness. In: Hartnett ME, Trese M, Capone Jr A, Keats BJB, Steidl SM (eds), Pediatric retina. Philadelphia USA: Lippincott Williams \& Wilkins, 2005, pp 315-329.

8 An international classification of retinopathy of prematurity. The committee for the classification of retinopathy of prematurity. Arch Ophthalmol 1984; 102: 1130-1134.

9 An international classification of retinopathy of prematurity. II. The classification of retinal detachment. The international committee for the classification of the late stages of retinopathy of prematurity. Arch Ophthalmol 1987; 105: 906-912.

10 Gilbert C, Foster A. Childhood blindness in the context of VISION 2020: the right to sight. Bull World Health Organ 2001; 79: 227-232.

11 Gilbert C, Rahi J, Eckstein M, O'Sullivan J, Foster A. Retinopathy of prematurity in middle-income countries. Lancet 1997; 350: 12-14.

12 Gilbert C, Fielder A, Gordillo L, Quinn G, Semiglia R, Visintin $\mathrm{P}$ et al. Characteristics of infants with severe retinopathy of prematurity in countries with low, moderate, and high levels of development: implications for screening programs. Pediatrics 2005; 115: e518-e525.

13 Markestad T, Kaaresen PI, Ronnestad A, Reigstad H, Lossius K, Medbo S et al. Early death, morbidity, and need of treatment among extremely premature infants. Pediatrics 2005; 115: 1289-1298.

14 Shah VA, Yeo CL, Ling YL, Ho LY. Incidence, risk factors of retinopathy of prematurity among very low birth weight infants in Singapore. Ann Acad Med Singapore 2005; 34: 169-178.

15 Jalali S, Matalia J, Hussain A, Anand R. Modification of screening criteria for retinopathy of prematurity in India and other middle-income countries. Am J Ophthalmol 2006; 141: 966-968.

16 Azad RV. Retinopathy of Prematurity: A Text and Atlas. 1st ed New Delhi: Jaypee Brothers Medical Publishers (P) Ltd, 2006.

17 Sehgal A, Telang S, Passah SM, Jyothi MC. Maternal and neonatal profile and immediate outcome in ELBW babies. Indian Pediatr 2003; 40: 991-995.

18 Sirtautiene R, Bagdoniene R. Threshold retinopathy of prematurity in Vilnius County: nine-year experience. Acta Medica Lituanica 2006; 13: 171-175.

19 Sirtautiene R, Bagdoniene R. Retinopathy of prematurity: is it time to change screening limits in Lithuania? Acta Medica Lituanica 2006; 13: 161-164.

20 Fang PC, Kuo HK, Ko TY, Chen CC, Hwang KP, Chung MY. Retinopathy of prematurity in larger preterm infants. Am J Perinatol 2006; 23: 273-277.

21 Fortes Filho JB, Lermann VL, Costa MC, Procianoy RS. Prevalência da retinopatia da prematuridade no Centro de
Neonatologia do Hospital de Clínicas de Porto Alegre. Arq Bras Oftalmol 2004; 67: 55 (Abstract).

22 Lermann VL, Fortes Filho JB, Procianoy RS. The prevalence of retinopathy of prematurity in very low birth weight newborn infants. J Pediatr (Rio J) 2006; 82: 27-32.

23 Graziano RM, Leone CR, Cunha SL, Pinheiro AC Prevalence of retinopathy of prematurity in very low birth weight infants. J Pediatr (Rio J) 1997; 73: 377-382.

24 Moraes NSB, Farah ME, Bonomo PP, Almeida MFB. Retinopatia da prematuridade: diagnóstico precoce e detecção de doenças oculares associadas. Arq Bras Oftalmol 1997; 60: 414 (Abstract)

25 Hiraoka M, Watanabe T, Kawakami T, Ito R, Takigawa I, Suzumura $\mathrm{H}$ et al. Retinopathy of prematurity in extremely low birth weight infants: a Tokyo multicenter study. Nippon Ganka Gakkai Zasshi 2004; 108: 600-605 (Abstract).

26 Hussain N, Clive J, Bhandari V. Current incidence of retinopathy of prematurity, 1989-1997. Pediatrics 1999; 104: e26.

27 O'Connor MT, Vohr BR, Tucker R, Cashore W. Is retinopathy of prematurity increasing among infants less than $1250 \mathrm{~g}$ birth weight? J Perinatol 2003; 23: 673-678.

28 Ells A, Hindle NW. Commentary on guidelines for screening for retinopathy of prematurity. Can J Ophthalmol 2000; 35: 253-254.

29 Lee SK, Normand C, McMillan D, Ohlsson A, Vincer M, Lyons $\mathrm{C}$. Evidence for changing guidelines for routine screening for retinopathy of prematurity. Arch Pediatr Adolesc Med 2001; 155: 387-395.

30 Subhani M, Combs A, Weber P, Gerontis C, DeCristofaro JD. Screening guidelines for retinopathy of prematurity: the need for revision in extremely low birth weight infants. Pediatrics 2001; 107: 656-659.

31 Patz A. Oxygen administration to the premature infant: a two-edged sword. Am J Ophthalmol 1967; 63: 351-353.

32 Saugstad OD. Oxygen for newborns: how much is too much? J Perinatol 2005; 25: S45-S49.

33 Saugstad OD. Oxygen and retinopathy of prematurity. J Perinatol 2006; 26: S46-S50.

34 Brown MS, Garcia JF, Phibbs RH, Dallman PR. Decreased response to plasma immunoreactive erythropoietin to "available" in anemia of prematurity. J Pediatr 1984; 105 793-798.

35 Hesse L, Eberl W, Schlaud M, Poets CF. Blood transfusion. Iron load and retinopathy of prematurity. Eur J Pediatr 1997; 156: 465-470.

36 Dani C, Reali MF, Bertini G, Martelli E, Pezzati M, Rubaltelli FF. The role of blood transfusions and iron intake on retinopathy of prematurity. Early Hum Dev 2001; 62: 57-63.

37 Ohls RK, Harcum J, Schibler KR, Christensen RD. The effect of erythropoietin on the transfusion requirements of preterm infants weighing $750 \mathrm{~g}$ or less: a randomized, double-blind, placebo-controlled study. J Pediatr 1997; 131: 661-665.

38 Yeo CL, Choo S, Ho LY. Effect of recombinant human erythropoietin on transfusion needs in preterm infants. J Paediatr Child Health 2001; 37: 352-358.

39 Brown MS, Baron AE, France EK, Hamman RF. Association between higher cumulative doses of recombinant erythropoietin and risk for retinopathy of prematurity. J AAPOS 2006; 10: 143-149. 